\title{
OBUKA ZAPOSLENIH ZA PRIMENU INFORMACIONIH SISTEMA KAO FAKTOR UNAPREĐENJA POSLOVANJAU UGOSTITELJSTVU
}

\author{
Ivana Blešić1, \\ Milan Ivkov', \\ Aljoša Tošić
}

\author{
${ }^{1}$ Departman za geografiju, turizam i \\ hotelijerstvo, \\ Prirodno-matematički fakultet, \\ Novi Sad, Srbija
}

\begin{abstract}
Rezime:
Nova tehnološka dostignuća i informacioni sistemi imaju sve veću ulogu u planiranju, organizaciji i izvršavanju operativnih zadataka u ugostiteljstvu, čineći ga jednostavnijim, efikasnijim i uspešnijim. Poslovanje i funkcionisanje ugostiteljske delatnosti zasniva se na postojanju informacija, njihovog protoka unutar sistema, kao i mogućnosti njihovog iskorišćavanja. Ovim radom biće predstavljen Garson, softverski paket za poslovanje u restoraterstvu. Takođe, biće prikazani rezultati istarživanja sprovedenog u 18 ugostiteljskih objekata u Novom Sadu. Dobijen je uzorak od 112 ispitanika obučenih za rad u softveru. Cilj rada je utvrđivanje stavova zaposlenih o programskom paketu Garson, njegovim mogućnostima, funkcionalnosti i značaju koji ima za unapređenje poslovanja ugostiteljskog objekta. Kroz sprovedeno istraživanje prikazani su i rezultati koji ukazuju na stepen zadovoljstva korisnika softverom i njegov značaj za razvoj praktičnih veština i kompetencija zaposlenih.
\end{abstract}

Ključne reči:

informacioni sistemi, Garson, edukacija zaposlenih.

\section{UVOD}

Od početka i nastanka ugostiteljstva, kao i većine uslužnih, privrednih i industrijskih grana, poslovanje i funkcionisanje se zasniva na postojanju informacija, protoka tih informacija unutar industrije, kao i efikasnosti i mogućnosti njihovog iskorišćavanja. Uspešno poslovanje ugostiteljskog preduzeća, na neki način, najviše se zasniva na sposobnosti menadžment tima za upravljanje informacijama i sistemom poslovanja.

Informacioni sistem može se definisati kao sistem u kome se veze između objekata i veze između sistema sa okolinom ostvaruju razmenom informacija. Informacioni sistem šire predstavlja uređeni integrisani skup podataka, procesa, interfejsa, mreža, tehnologija i ljudi koji su u međusobnoj korelaciji u cilju podrške i poboljšanja svakodnevnih poslovnih operacija [1]. Jedna od najopštijih definicija pod informacionim sistemom podrazumeva skup metoda, postupaka i resursa oblikovanih tako da bi se ostvarilo postizanje nekog cilja [2]. Uska povezanost informacionih sistema i informacionih tehnologija zasniva se na većem protoku informacija kroz i unutar sistema, na brži i efikasniji način. Dostupnost informacija i njihovo pravilno iskorišćavanje vitalno je prilikom
Correspondence:

Ivana Blešić

e-mail:

ivana.blesic@dgt.uns.ac.rs 
upravljanja i organizovanja preduzeća, odnosno bilo kojeg vrsta posla [3]. Osnovne komponente informacionog sistema su: ljudi, oprema, procesi, podaci i informacioni tokovi [4]. Takođe, informacioni sistemi mogu se smatrati i organizacionim, jer im je namena prikupljanje i pružanje informacija korisnicima u jednom ili u više različitih poslovnih sistema. Informacija postaje upravljački resurs koji je podjednako važan, kao ljudski resursi ili kapital [5].

\section{Informacione tehnologije u turizmu i ugostiteljstvu}

Razvoj informacionih sistema i tehnologija u turizmu direktno je uticao na potrebu uvođenja novih sistema i tehnologija u ugostiteljstvu, ali i na isti način podstakao proizvođače da prilagode softvere i tehnologiju potrebama hotelijerskog i restoraterskog poslovanja. Povećano interesovanje velikog broja turista za korišćenjem turističkog proizvoda, i svih elemenata u sklopu tog proizvoda, imalo je za posledicu stvaranje novih sistema i tehnologija, povezanih na globalnom i internacionalnom nivou.

Primena informacione i kompjuterske tehnologije $\mathrm{u}$ turizmu može se posmatrati kroz četiri ključna perioda [6]:

1. Period od 60-ih godina 20. veka, tzv. era prikupljanja podataka. Karakteriše je upotreba ogromnih i skupih kompjutera kojim su raspolagale velike avio-kompanije. Godine 1964. američka avio-kompanija American Airlines uvodi onlajn rezervacioni sistem za prodaju sopstvenih avio karata (SABRE).

2. Period 70-ih godina 20. veka ili doba razvoja upravljačkog menadžmentskog informacionog sistema (MIS), kada se on koristi za interno upravljanje i koordinaciju.

3. Period 80-ih godina 20. veka karakteriše razvoj strategijskog informacionog sistema (SISs), (hotelijeri, organizatori putovanja). To je period razvoja personalnih računara (PS). U ovom periodu razvijaju se dva ključna operativna sistema (DOS, WINDOWS).

4. Za period 90-ih godina 20. veka najznačajnija je pojava World Wide Web-a (www), i veliki i brz uticaj interneta na turističke delatnosti. Pojavljuju se turistički sajtovi koji se bave putovanjima (Expedia, Travelocity, Prewiew Travel).

5. Peti period u primeni savremene informacione $\mathrm{i}$ komunikacione tehnologije, obeležen je kroz razvoj interneta, mobilnih komunikacija i interaktivne digitalne televizije, koja povezuje turističku tražnju sa turističkom ponudom kao i ponude međusobno.
Gotovo sve delatnosti povezane sa turizmom i ugostiteljstvom prilagođavale su svoj način rada uvođenjem novih tehnologija i sistema potrebama modernijeg tržišta. Sve manuelne funkcije zamenjene su kompjuterizovanim, ne samo kako bi se način rada modernizovao, već i zbog potrebe tržišta i tražnje za bržom i lakšom obradom podataka. Takođe, dolazi do lakšeg uključivanja u globalne mreže svih preduzeća i industrija u turizmu. Najznačajnije forme IT u turizmu ogledaju se kroz upotrebu rezervacionih sistema, softverskih aplikacija u ugostiteljstvu, sistema za podršku upravljanja destinacijama, elektronsko posredovanje $u$ organizaciji putovanja putem interneta, geografskih informacionih sistema, mobilnih platformi i dr.

Uz pomoć IT tehnologije obavljaju se sledeći poslovi u turizmu [2]:

- Direktni kontakt sa klijentima i partnerima: rezervacije, prijave/odjave, plaćanje;

- Kancelarijski poslovi: računovodstva, platni spiskovi, upravljanje kadrovima, marketing;

- Zabava i usluge za klijente;

- Komunikacija sa kupcima i partnerima;

- Istraživanje tržišta;

- Reakcija i upravljanje kriznim situacijama;

- Fleksibilno i dinamičko određivanje cena kroz upravljanje prihodima;

- Diferencijacija i personalizacija proizvoda;

- Kontrola pokazatelja realizacije i izgradnja mehanizma povratne veze;

- Upravljanje poslovnim procesima i osobljem i dr.

Bez šire primene automatizacije poslovnih operacija u svim sektorima rada, uključivanje hotelijerstva kao materijalne osnove turizma u globalne distributivne sisteme nije moguće. „Informatički bum”, nezadrživ prodor kompjuterske tehnologije, globalno umrežavanje na svim nivoima, nametnulo je međunarodnom hotelijerstvu uspostavljanje novih standarda. Standardizacija poslovnih informacija zasnovana na kompjuterizaciji rada svih organizacionih celina u objektima hotelijerstva, odnosno automatskom registrovanju svih promena, uz obezbeđenje međusektorske komunikacije i protoka svih informacija relevantnih za poslovanje, ogleda se u uvođenju jedinstvenog sistema upravljanja objektom (Property Management System - PMS) [7]. Property Management Systems - PMS su kompjuterizovani sistemi koji softverom olakšavaju sve vrste upravljanja poslovnim procesima. Uvođenje PMS-a u hotel ima mnoge prednosti, a neke od njih su efikasnije obavljanje zadataka, pružanje preciznih informacija o okupiranosti hotela, stvaranje baze podataka, planiranje za potrebe marketinga itd. [8]. 


\section{Programski paket za ugostiteljstvo Garson}

Garson, programski paket kompanije 2D Soft Novi Sad, obuhvata kompletno poslovanje ugostiteljskih objekata kroz praćenje naplatnih, proizvodnih i uslužnih mesta. Namenjen je različitim vrstama ugostiteljskih objekata. Zavisno od veličine i tipa objekta, kreira se sistem sačinjen od POS aplikacija (izdavanje porudžbina, naplata), administratorskih modula (magacini, zalihe, artikli, zaposleni, VIP gosti, promocije, izveštaji) i POS opreme (fiskalni štampači i štampači za kuhinju, bar-kod skeneri, prenosivi ručni PDA računari, touchscreen monitori, čitači kartica). S obzirom na kriterijume, Garson pruža mogućnost korišćenja više komponenti svog softvera i oni su podeljeni na: Garson POS, Garson Backoffice i Garson Mobile Suite.

Garson POS podrazumeva programski operativni sistem koji se u radu ugostiteljskih objekata koristi svakodnevno. Svojim brojnim funkcijama i opcijama pruža mogućnost ugostiteljskim radnicima širok spektar operacija i olakšava im svakodnevni rad. Garson POS je program kojim se služe konobari i šankeri za kucanje porudžbina, izdavanje računa i vođenje evidencije o izdatim jelima i pićima, kao i zaduženjima gostiju i ostalih klijenata unutar objekta. Grafički prikaz restorana i rasporeda stolova, prepoznatljive slike artikala, evidencija različitih načina plaćanja, štampanje posebnih naloga za šank i kuhinju i prikaz dnevnog poslovanja garantuju na POS mestu precizan i brz rad.

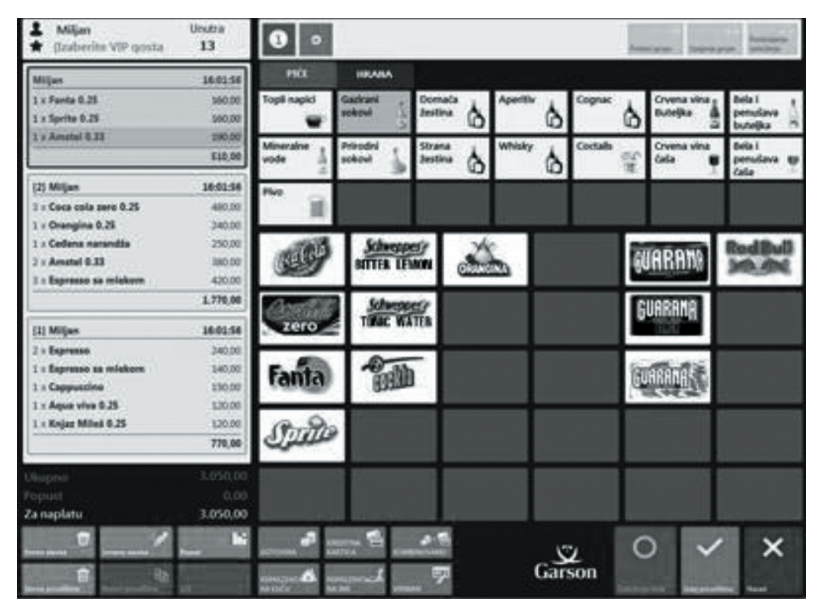

Slika 1. Garson POS - radna površina softvera.

Izvor: [9].

Funkcionalnosti Garson Backoffice-a kao samostalnog dela softvera su konfigurisanje sistema za pojedinačne objekte ili za više objekata u okviru istog preduzeća, podešavanje proizvoda, usluga, cenovnika, normativa, dodatnih opisa i ostalih osobnih artikala, mogućnost upravljanja većim brojem različitih magacina, kreiranje i podešavanje loyalty programa, mogućnost praćenja i kontrolisanja prodaje u ugostiteljskom objektu i $\mathrm{dr}$.

Garson Mobile Suite predstavlja program ili aplikaciju za Android mobilne telephone, ili neke druge elektoronske uređaje slične namene, preko kojih se može direktno upravljati Garsonom i obavljati sve funkcije koje Garson inače omogućava. Aplikacija koju konobari, menadžeri, pa čak i gosti mogu i koriste svakodnevno u radu ili poseti restoranu, predstavlja novu dimenziju poslovanja za restorane i druge ugostiteljske objekte [10].

\section{REZULTATI ISTRAŽIVANJA}

\section{Opis i metodologija istraživanja}

Anketno istraživanje tehnikom „licem u lice” izvršeno je tokom 2014. i 2015. godine. Podeljeno je ukupno 200 anketa u 18 ugostiteljskih objekata u Novom Sadu (restorana, vinoteka i kafe-barova). Dobijen je uzorak od 112 validno popunjenih anketnih upitnika. Cilj istraživanja bio je utvrđivanje stavova zaposlenih u ugostiteljskim objektima o programskom paketu Garson i njegovom značaju za unapređenje poslovnih procesa.

Upitnik korišćen u ovom istraživanju sastoji se iz dva dela. Prvi deo čine pitanja koja se odnose na sociodemografske podatke ispitanika, kao i dva opšta pitanja o softverskom paketu Garson. Drugi deo upitnika sastoji se od 38 pitanja u vidu iskaza kojima se meri zadovoljstvo korisnika obukom i programskim paketom. Ispitanici su označavali stepen slaganja sa iznetim tvrdnjama zaokruživanjem jednog od brojeva na Likertovoj petostepenoj skali od 1 (Uopšte se ne slažem) do 5 (U potpunosti se slažem).

\section{Opis uzorka}

U objektima u kojima je sprovedeno istraživanje, zaposleno je više osoba muškog $(67,9 \%)$ nego ženskog $(32,1 \%)$ pola, što je naročito izraženo u restoranima. Što se tiče starosne dobi zaposlenih, gotovo polovina ispitanika čini starosnu grupu između 26 i 35 godina (47,3\%). Najmanji broj zaposlenih pripada starosnoj grupi od 36 do 45 godina (17,9\%). Što se tiče stručne spreme, najveći broj ispitanika (58\%) ima završenu srednju školu, uglavnom ugostiteljsku, odnosno turističku. Višu stručnu spremu ima 33\%, a visoku $8,9 \%$ ispitanika. Istraživanjem je utvrđeno da $13,4 \%$ ispitanika ima radno iskustvo u 
oblasti ugostiteljstva do godinu dana. Ispitanici čije se radno iskustvo kreće od 2 do 5 godina u uzorku učestvuju sa $38,4 \%$, a od 6 do 10 godina sa $31,3 \%$. Ispitanici koji u ugostiteljskoj branši imaju između 11 i 15 godina radnog staža zastupljeni su sa $17 \%$.

Na pitanje o iskustvu sa drugim softverskim paketima, $58,9 \%$ ispitanika je odgovorilo da je pre rada u Garsonu imalo prilike da radi u sličnim softverima (Liman Soft, TokyoPos, Micros, SkyPos).

Rezultati deskriptivne statističke analize $i$ t-testa nezavisnih uzoraka

Aritmetičke sredine ocena 38 pitanja koja su bila vezana za funkcionalnost i jednostavnost primene softvera Garson kretale su se od 1,982 (Pojedini simboli koji postoje vas zbunjuju, nisu dobro predstavljeni) do 4,598 (Program je fleksibilan prilikom naplate zaduženja i Zadovoljan sam primenom softverskog sistema Garson). Visoke ocene (iznad 4) dobile su i tvrdnje koje se odnose na: grafički prikaz rasporeda stolova u restoranu, jednostavnost softvera za upotrebu, korišćenje svih opcija sistema u svakodnevom radu, jednostavno savladavanje svih opcija softvera, jednostavnost pronalaženja svih portebnih aplikacija, mogućnost uvida u strukturu svih podataka i sl. Čak 24 pozitivno formulisanih tvrdnji ocenjeno je prosečnom ocenom iznad 4.

Pitanja čija se aritmetička sredina kreće između 3 i 4 predstavljaju pitanja koja su najčešće ispitanicima bila nejasna, ili nisu imali informacije na osnovu kojih bi mogli da daju odgovor. Tvrdnje kao što su Isporuka i instalacija ovog programa je kratko trajala, Uložena finansijska sredstva za instaliranje ovog softverskog sistema opravdala su očekivanja i Zaposleni su imali kvalitetnu obuku predstavljaju tvrdnje u odnosu na koje većina ugostiteljskih radnika nije imala stav pa su davali ocenu 3 - neodređeno.

Tvrdnje koje su ocenjene prosečnim ocenama ispod 3 su negativno formulisane, odnosno, usmerene su na nedostatke softvera. Niske vrednosti ocena kod ovih pitanja, kao npr. Često se dešava da se sistem prilikom upotrebe blokira, Potrebno je dosta vremena da se vrati funkcija sistema ukoliko dođe do kočenja, i tvrdnja koja se odnosi na grafički deo sistema Pojedini simboli koji postoje vas zbunjuju, nisu dobro predstavljeni, ukazuju da se većina ispitanika ne slaže da program ima navedene nedostatke.

\begin{tabular}{|c|c|c|c|}
\hline Pitanja & Grupe & $\begin{array}{l}\text { Aritmetička } \\
\text { sredina }\end{array}$ & $\mathrm{t}$ \\
\hline \multirow{2}{*}{$\begin{array}{l}\text { Prikaz rasporeda stolova i } \\
\text { reona u sistemu je realna } \\
\text { kao u objektu. }\end{array}$} & $\mathrm{da}$ & 4,6364 & \multirow{2}{*}{$2,510^{* *}$} \\
\hline & ne & 4,2174 & \\
\hline \multirow{2}{*}{$\begin{array}{l}\text { Razvrstavanje artikala po } \\
\text { grupama je jednostavno i } \\
\text { olakšava svakodnevni rad. }\end{array}$} & da & 4,6061 & \multirow{2}{*}{$2,412^{* *}$} \\
\hline & ne & 4,3478 & \\
\hline \multirow{2}{*}{$\begin{array}{c}\text { Aplikacije koje se koriste } \\
\text { usklađenesu sa zadacima } \\
\text { koji treba da se obavljaju } \\
\text { u svakodnevnom } \\
\text { poslovanju. }\end{array}$} & $\mathrm{da}$ & 4,1061 & \multirow{2}{*}{$2,403^{\star *}$} \\
\hline & ne & 3,7609 & \\
\hline \multirow{2}{*}{$\begin{array}{l}\text { Dobijanje informacija iz } \\
\text { ovog sistema na vreme } \\
\text { unapređuje kvalitet mog } \\
\text { rada. }\end{array}$} & $\mathrm{da}$ & 4,3939 & \multirow{2}{*}{$2,326^{\star *}$} \\
\hline & ne & 3,5870 & \\
\hline \multirow{2}{*}{$\begin{array}{c}\text { Informacije koje su } \\
\text { sadržane u ovom sistemu } \\
\text { su dovoljne da obavljam } \\
\text { svoj posao. }\end{array}$} & $\mathrm{da}$ & 4,5758 & \multirow{2}{*}{$2,243^{* *}$} \\
\hline & ne & 4,0000 & \\
\hline \multirow{2}{*}{$\begin{array}{l}\text { Ovaj sistem je dizajniran } \\
\text { za sve nivoe korisnika. }\end{array}$} & da & 4,2727 & \multirow{2}{*}{$4,899^{*}$} \\
\hline & ne & 3,8043 & \\
\hline \multirow{2}{*}{$\begin{array}{l}\text { Omogućeno je kreiranje } \\
\text { raznovrsnih izveštaja i } \\
\text { statistika. }\end{array}$} & da & 4,4091 & \multirow{2}{*}{$4,532^{\star}$} \\
\hline & ne & 3,7174 & \\
\hline \multirow{2}{*}{$\begin{array}{l}\text { Dodeljivanje VIP statusa } \\
\text { klijentima i pronalaženje } \\
\text { istih u sistemu je } \\
\text { jednostavna i brza. }\end{array}$} & da & 4,1364 & \multirow{2}{*}{$2,553^{\star *}$} \\
\hline & ne & 3,7826 & \\
\hline \multirow{2}{*}{$\begin{array}{l}\text { Fleksibilan je prilikom } \\
\text { naplate zaduženja. }\end{array}$} & da & 4,7121 & \multirow{2}{*}{$4,043^{*}$} \\
\hline & ne & 4,4348 & \\
\hline \multirow{2}{*}{$\begin{array}{l}\text { Povezanost ovog sistema } \\
\text { sa drugim sistemima } \\
\text { unutar objekta je efikasna. }\end{array}$} & da & 4,1818 & \multirow{2}{*}{$3,610^{*}$} \\
\hline & ne & 3,5870 & \\
\hline \multirow{2}{*}{$\begin{array}{l}\text { Često se dešava da se } \\
\text { sistem prilikom upotrebe } \\
\text { blokira. }\end{array}$} & da & 2,2727 & \multirow{2}{*}{$-3,908^{\star}$} \\
\hline & ne & 3,1957 & \\
\hline \multirow{2}{*}{$\begin{array}{c}\text { Potrebno je dosta } \\
\text { vremena da se vrati } \\
\text { funkcija sistema ukoliko } \\
\text { dođe do kočenja. }\end{array}$} & da & 2,3333 & \multirow{2}{*}{$-3,757^{\star}$} \\
\hline & ne & 3,1739 & \\
\hline \multirow{2}{*}{$\begin{array}{l}\text { Zadovoljan sam prikazom } \\
\text { simbola koji postoje. }\end{array}$} & da & 4,6970 & \multirow{2}{*}{$2,491^{\star *}$} \\
\hline & ne & 4,3913 & \\
\hline \multirow{2}{*}{$\begin{array}{l}\text { Pojedini simboli koji } \\
\text { postoje vas zbunjuju, nisu } \\
\text { dobro predstavljeni. }\end{array}$} & $\mathrm{da}$ & 1,7424 & \multirow{2}{*}{$-2,668^{\star}$} \\
\hline & ne & 2,3261 & \\
\hline \multirow{2}{*}{$\begin{array}{l}\text { Dokazane su uštede } \\
\text { prilikom korišćenja ovog } \\
\text { softverskog sistema. }\end{array}$} & $\mathrm{da}$ & 3,7121 & \multirow{2}{*}{$2,560^{*}$} \\
\hline & ne & 3,2174 & \\
\hline
\end{tabular}

Tabela 2. T-test nezavisnih uzoraka u odnosu na ranije iskustvo u korišćenju Garsona i sličnih softvera ( $d a-$ imali su iskustvo; $n e$ - nisu imali iskustvo) ${ }^{\star} \mathrm{p}<0,01 ;{ }^{* *} \mathrm{p}<0,05$ 
T-test nezavisnih uzoraka primenjen je sa ciljem upoređivanja aritmetičkih sredina odgovora između ispitanika u odnosu na ranije iskustvo u korišćenju Garsona i sličnih softvera. Rezultati testa su pokazali da se ocene ispitanika statistički značajno razlikuju (na nivou $\mathrm{p}<0,01$ i p $<0,05)$ kod 15 pitanja. Rezultati su pokazali da zaposleni koji su imali ranije iskustvo sa korišćenjem sličnih softverskh paketa imaju pozitivniji stav prema informacijama kojima se rukuje preko sistema i koje su sadržane u njemu. Takođe, sa već ranijim iskustvom u korišćenju sličnih softvera, ti ispitanici imaju manje poteškoće prilikom rada i mnogo bolje ocenjuju sistem od onih koji ga prvi put koriste.

\section{ZAKLJUČAK}

Kao rezultat istraživanja softverskog proizvoda Garson, kao i anketiranja zaposlenih koji ga svakodnevno koriste u ugostiteljskim objektima, dolazi se do zaključka da obuka zaposlenih za korišćenje softverskog paketa ima značajan doprinos za unapređenje poslovnih procesa u ugostiteljstvu. Garson i slični softveri predstavljaju jedan od faktora inovacija koje su neophodne za uspešno poslovanje. Sistem u kojem je protok informacija tačno definisan i određen, i koji pruža sve mogućnosti svojim fleksibilnim funkcijama, sprečava nastanak grešaka u poslovnim procesima i samim tim unapređuje kvalitet ugostiteljskih usluga. Ovaj softver svojim funkcijama maksimalno štedi vreme zaposlenima, pruža im mogućnost lakog korišćenja i kretanja kroz sistem, ostavljajući im više vremena za sam proces pružanja usluge kroz orijentaciju prema gostu. Grafički izgled softvera predstavlja olakšanje zaposlenima prilikom pronalaženja željenih artikala i neophodnih funkcija. Sprečavanje nepotrebnog gubljenja vremena, kao i znatno ubrzan protok informacija između sektora ugostiteljskog objekta, predstavlja najveći doprinos softvera za unapređenje poslovanja u ugostiteljskim objektima. Na osnovu sprovedenog istraživanja, može se izvesti zaključak da su anketirani zaposleni generalno zadovoljni primenom Garsona, da se lako prilagođavaju na njegove aplikacije i da je svakodnevno obavljanje zadataka u njemu jednostavno i u velikoj meri olakšava rad u ugostiteljskoj delatnosti.

Preporuke autora su da se istraživanje sprovede i tokom 2017. godine u cilju dobijanja većeg uzorka i preciznije slike o značaju informacionih sistema za razvoj ugostiteljske delatnosti. Takođe, neophodno je formirati stratifikovan uzorak i ispitati postojanje statistički značajnih razlika u stavovima zaposlenih u odnosu na njihove sociodemografske karakteristike. Autori očekuju da će rezultati budućih istraživanja ukazati na pozitivan stav zaposlenih prema informacionim sistemima koje koriste.

\section{LITERATURA}

[1] A. Njeguš, Informacioni sistemi u turističkom poslovanju. Univerzitet Singidunum, Beograd, 2010.

[2] U. Stankov, Informacione tehnologije u turizmu, autorizovana skripta. Prirodno-matematički fakultet, Departman za geografiju, turizam i hotelijerstvo, Novi Sad, 2010.

[3] V. Galičić i S. Ivanović, Informacijska tehnologija i organizacijska kultura hotelskih poduzeća. Fakultet za turistički i hotelski menadžment u Opatiji, Sveučilište u Rijeci, Rijeka, 2008.

[4] Ž. Marčićević i Z. Marošan, Primena informacionih tehnologija. Visoka škola strukovnih studija, Novi Sad, 2010.

[5] J. Poliščuk, Projektovanje informacionih sistema. Univerzitet u Podgorici, Podgorica, 2007.

[6] O. Bakić, Marketing u turizmu. Univerzitet Singidunum, Beograd, 2010.

[7] LJ. Kosar, Hotelijerstvo. Viša hotelijerska škola, Beograd, 2005.

[8] T. Pavlović, Sektor soba - Rooms Division. FRAME Media, Beograd, 2011.

[9] http://mindnever.com/work/2dsoft/sr_ugostiteljstvo_garson.htm

[10] http://www.2dsoft.com/rs/garson 